NOT I C E

THIS DOCUMENT HAS BEEN REPRODUCED FROM MICROFICHE. ALTHOUGH IT IS RECOGNIZED THAT CERTAIN PORTIONS ARE ILLEGIBLE, IT IS BEING RELEASED IN THE INTEREST OF MAKING AVAILABLE AS MUCH INFORMATION AS POSSIBLE 


\title{
Health Requirements for Advanced Coal Extraction Systems
}

\author{
Wayne F. Zimmerman
}

(NASA-CR-163265) HEALTH REQUIREMENTS FOR
ADVANCED COAL EXTRACTION SYSTEMS (Jet
Propulsion LAb.) 28 P HC A03/MF A01 $\operatorname{CsCL} 06 \mathrm{~J}$

N $80-34093$

Unclas

G3/52 29036

September 15, 1980

Prepared for

U.S. Department of Energy

Through an agreement with National Aeronautics and Space Administration by

Jet Propulsion Laboratory California Institute of Technology Pasadena, California

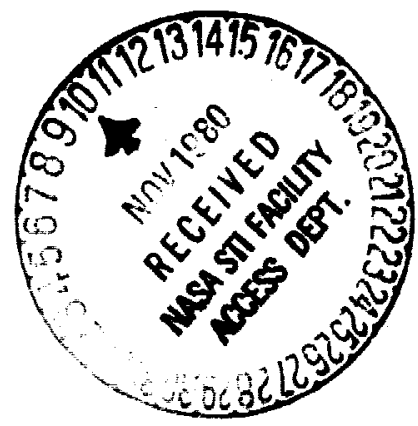




\title{
Health Requirements for Advanced Coal Extraction Systems
}

\author{
Wayne F. Zimmerman
}

September 15, 1980

\section{Prepared for}

U.S. Department of Energy

Through an agreement with

National Aeronaulics and Space Administration

by

Jel Propulsion Laboratory

Californa Instifute of Technology

Pasadena. Califoma 
Prepared by the Jet Propulsion Laboratory, California Institute of Technology. for the U.S. Department of Energy Itrough an ayreement with the National Aetonautics and Space Administration.

This report was prepared as an account of work sponsored by the United States Government. Neither the United States nor the United States Department of Finery, nor any of their employees, nor any of their contraclors, subcontractors, or their employees, makes any warranty. express or implied. or assumes any legal liability of responsibility for the accuracy. completeness or uscfulness of any information. apputstus, product of process disclused, of represents that its use Would not infringe privately owned rights. 


\begin{abstract}
Health requireaente have been developed as long-range goals for future advanced coal extraction syotems which would be introduced into the market in the year 2000 . This document sumarises those requirements and presents the analyses and data supporting them.

The goal of the requirements is that underground coal miners work in an environment that is as close as possible to the working conditions of the general population, that they do not exceed mortality and morbidity rates resulting from lung diseases that are comparable to those of the general population, and that their working conditions comply as closely as posaible to those of other industries as specified by OSHA regulations.

The primary health requirements for advanced coal xtraction systems are that coal duat be reduced to 1 ess than $2 \mathrm{mg} / \mathrm{m}^{3}$ to reduce the incidence of chronic lung diseases in miners, and that carcinogens and mutagens be reduced to levels typical of the air in large urban centers. Secondary requirements are that: (1) relative humidity be between $50 \%$ and $75 \%$ and that temperature be between $65^{\circ} \mathrm{F}$ and $78^{\circ} \mathrm{F}$, with no extreme swings in either; (2) noise and lighting levels conform to present MSHA standards; (3) working space accomodate most body configurations, and (4) vibration damping equipment be provided.

A brief technique for evaluating whether proposed advanced syitems meet these safety requirements is presented, as well as a discussion of the costs of respiratory disability compensation. Appendices describe the effects of coal dust ingestion, suggest a recommended technique for detecting potential carcinogens, and present tables of accepted working space standards.
\end{abstract}


FOREWORD

This document is one of a series which describe systems level requirements for advanced underground coal mining equipment. These requirements are sumarized in "Overall Requirements for an Advanced Underground Coal Extraction System," JPL Publication 80-39 by Martin Goldsmith and Milton, L. Lavin. Five areas of performance are discussed:

(1) Production cost.

(2) Miner safety.

(3) Miner health.

(4) Environmental impact.

(5) Recovery efficiency.

The report which follows presents details of the analysi: used to formulate the health requirements.

This work is part of an effort to define and develop innovative coal extraction systems suitable for the significant resources remaining in the year 2000. Sponsorship is provided by the office of Mining, United States Department of Energy via an interagency agreement with the National Aeronautics and Space Administration. William B. Schmidt, Director of the Office of Mining, is the project officer.

\section{ACKNOWLEDGMENT}

The author would like to acknowledge the assistance provided by Dr. Myron Goodman, Department of Biological Sciences, University of Southern California, and Dr. Melvyn Rosenstein, M.D. Special acknowledgments are also extended to Dr. L. Kerr, M.D., Director of Occupational Health, UMWA; and the USC Medical Center Lung Physiology Department, for their contributions. 


\section{SECTION I}

\section{HEALTH REQUIREMENTS}

\section{A. INTRODUCTION}

The coal mining industry has been considered inherently unhealthful because of the difficulty of controlling exposure to a wide variety of environmental conditions. Furthermore, these conditions affect many of the major physiological subsystems: the respiratory, cardiovascular, hormonal, and sensory. The key factors contributing to the degradation of these systems are dust (e.g., coal, quartz), humidity and temperature extremes, methane gas, diesel emissions, poor lighting, noise, and vibration. In addition to these factors, the psychological problems resulting from working in small, closed, unlighted spaces also aggravate the health problem. Therefore, any advanced coal extraction system should provide a substantial improvement in health conditions, either through improvement of the mine environment or isolation of miners from the envi ronment.

\section{B. FIGURE OF MERIT}

The basic philosophy behind the development of the health requirements was to establish, if possible, figures of merit against which to compare the projected performance of new systems. During the -tudy it became apparent that no such figure of merit was available. Whereas in the case of safety one might select an average yearly injury rate based on other similar industries as a figure of merit, healch cannot be viewed in the same manner because the effects of unhealthful working conditions must be measured over a period much greater than one year. For example, pneumoconiosis, respiratory disease typically related to the coal mining industry, usually takes twenty years before its physical effects become apparent. Therefore, the figure of merit for health must measure the differences between cosl miners and workers in other industries, recognizing that these differences might not materialize for the greater part of a lifetime. The first measure that seemed to fit this criterion was "mortality". However, when the mortality rates for coal workers and the average male population were examined, the mortality rates were not significantly different. Figure 1-1 illustrates that the 1 ife expectancy of coal miners is only $3 \%$ less than the general male population. This is not a significant enough difference to make any firm comparative statements about coal miner mortality rates and those of the general male population. In addition to this, the data presented in Figure 1-1 do not provide the best comparison of mortality because all classes of laborers are included in the general population. A more accurate comparison would have been two similar populations (e.g., coal miner mortalities from West Virginia compared to construction laborer mortalities from the same geographical area). However, epidemiological studies relating to groups as specific as 


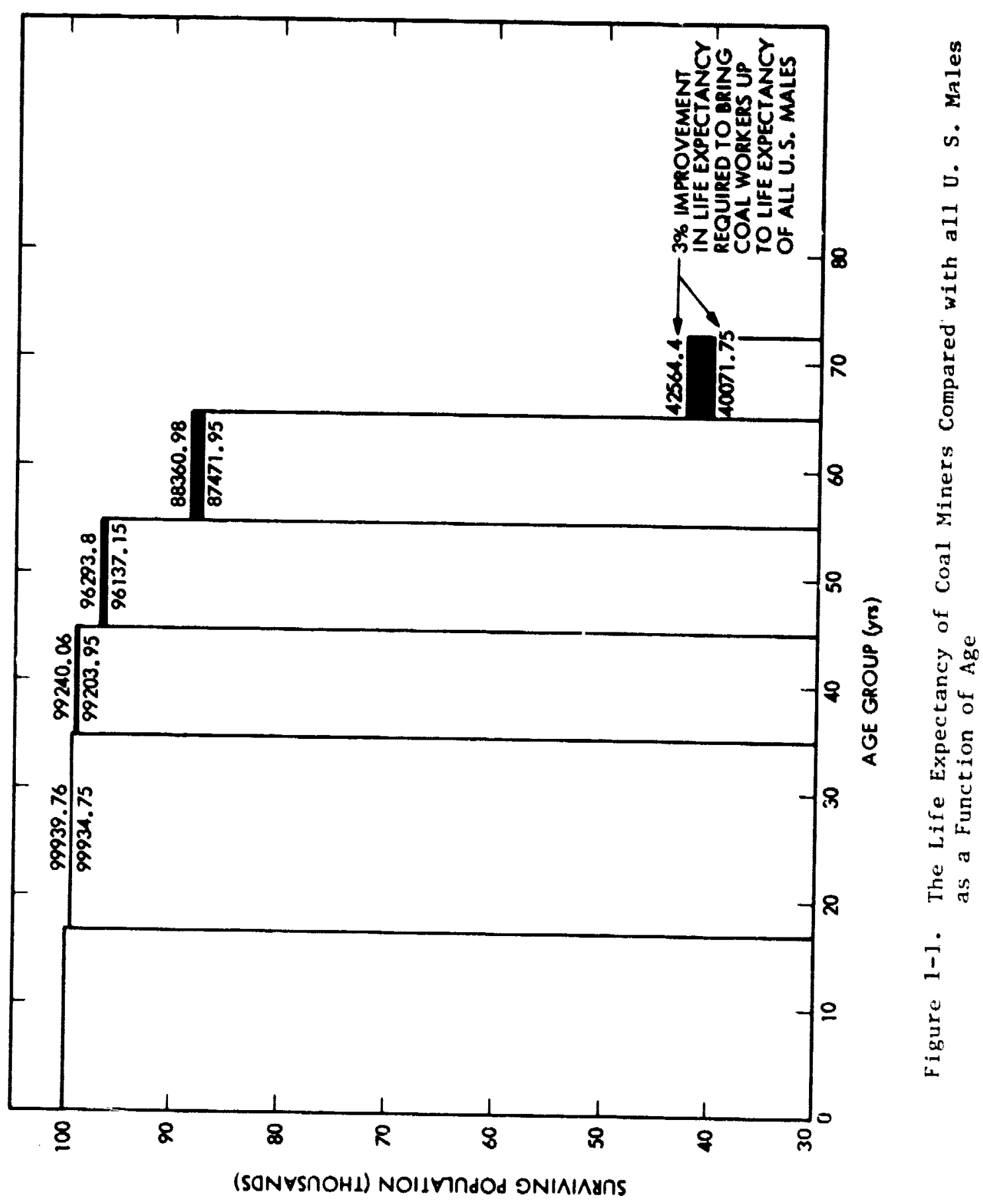


these generally do not exist. Because miner mortalities are not significantly different from those of the general population, it was decided not to use mortality as a figure of merit. One useful result the mortality study did provide, however, was that coal miners deviated significantly from the general male population in the inciderce of respiratory dissase. Table 1-1 indicates that a significantly larger number of cosl miners will die from respiratory diseases, compared to the general male population. Pneumoconiosis is caused by coal dust which results from the cutting process. Very small particles inhaled into the lungs become trapped in the lung alveolar tissues, and, if inhaled in a large enough quantity, eventually cause a reduction in air transfer into the blood. Other diseases such as emphysema, bronchospasm, or pneumonia are aggravated by both small and large dust particles generated during the cutting process, as well as the cold and damp environments typical of many underground mines. Thus, the mine environment is the prime reason why miners suffer respiratory ailments to a larger degree than the rest of the male population.

One interesting aspect of most of the respiratory diseases shown in Table $1-1$ is that they are chronic, or long term, in nature. Although a miner may not necessarily die sooner than the average person, he may be disabled for a long period of time. This led to the consideration of "morbidity" as a figure of merit. This presented a problem because it was difficult to obtain detailed information on respiratory disability in the coal mining industry compared to other similar industries such as metal and non-metal mining. Though some disability information was obtained for a small number of industries, it was difficult to evaluate a new design and quantitatively determine to what degree respiratory disability might be reduced. Variation in an individual's susceptibility to disease, and varying lengths of exposure to harmful elements in the environment contribute to the uncertainty with which one can project reductions in disability. Therefore, morbidity also appeared unusable as a figure of merit. Though morbidity measured in terms of "active years lost", for example, was not practical for evaluating new systems, the idea of reducing "disability" still appeared to be a valid goal. It was therefore decided to identify the major causes of disability, and evaluate new systems based on their ability to reduce or remove these causes, rather than evaluate them against a figure of merit.

\section{HFALTH REQQUIRFMENTS SUMMARY}

The major causes of disability that occur in the underground coal mine environment are: 1) coal and other mineral dust, 2) carcinogens and mutagens such as aromatic hydrocarbons (found in trace form within the coal seam), 3) temperature and humidity extremes, 4) poor lighting, 5) noise and 6) vibration. Psychological stress induced by working in the mine orivironment was not considered as a cause of disability but as an important alement that could contribute to poor hralth. 
Table 1-1. Observed Coal Miner Deaths, Expected Total U.S. Male Deaths, and Standardized Mortality Ratios (SMR) for Selected Diseases

(Data from a sample of 22,998 coal miners in Rockette, H., Mortality Among Coal Miners Covered by the unwh Health Retirement Funds, March 1977. The 1965 U.S. male population was used to compute the expected number of deaths.)

\begin{tabular}{|c|c|c|c|}
\hline CAUSE OF DEATH & $\begin{array}{l}\text { OBSERVED COAL } \\
\text { MINER DEATHS }\end{array}$ & $\begin{array}{l}\text { EXPECTED } \\
\text { DEATHS* }\end{array}$ & SMR $\star \star$ \\
\hline Major Cardiovascular Diseases & 4285 & 4525.9 & 94.7 \\
\hline All Malignant Neoplasms & 1223 & 1248.2 & 98.0 \\
\hline Diabetes & 64 & 110.2 & 58.1 \\
\hline $\begin{array}{l}\text { Non-malignant Respiratory } \\
\text { Disease (includes diseases } \\
\text { below plus others) }\end{array}$ & 741 & 471.6 & 157.1 \\
\hline Influenza & 28 & 8 & 340.6 \\
\hline Primary Atypical Pneumonia & 23 & 12.8 & 179.7 \\
\hline $\begin{array}{l}\text { Chronic Interstitial } \\
\text { Pneumonia }\end{array}$ & 58 & 16.4 & 353.7 \\
\hline Bronchiectasis & 11 & 9 & 122.1 \\
\hline Emphysema & 170 & 134.6 & 126.3 \\
\hline Pneumoconiosis & 187 & $20.2($ est.) & 925.7 \\
\hline Asthma & 32 & 18.3 & 174.9 \\
\hline
\end{tabular}

*In the same number $(22,998)$ of U.S. males

*tThe standardized Mortality Ratio (SMR) is determined by dividing the observed deaths by the expected deaths, and multiplying by 100 . An SMR of 100 implies no distinguishable difference between coal miners and the general population. 
Table 1-2. Sumary of Advanced Coal Extraction

Systen Health Requirewents

Heal th

Characteristics

Goal

Requirewent

PRIMARY REQUIREMENTS

Dust

Carcinogens and

Mutagens

SECONDARY REQUIREMENTS

Temperature

Humidity

Noise

Lighting

Working Space

Vibration
Reduce miner mortality and worbidity resulting from lung disease to that of U.S. male population

Reduce ainer mortality and morbidity resulting from lung diseases to that of U.S. male population

Permit miners to work in environment sat is fying OSHA and MSHA standards for other industries

Same a above

Same as above

Same as above

Same as above

Same as above
No greater than $2 \mathrm{mg} / \mathrm{m}^{3}$

Concentiations no ereater than that in air of large urban areas

Between $65^{\circ} \mathrm{F}$ and $78^{\circ} \mathrm{F}$ with no extreme swings

Between $50 \%$ and 75\% with no extreme suing

Meet MSHA

standarda

Meet MSHA standards

Accomodate most body configurations as shown in Appendix C

Provide vibration damping for machinery operators 
Respiratory disease is the major cause of serious miner disability and death. Dust and carcinogens contribute largely to this, and requiremente aimed at reducing these causes were therefore termed "primary". The teaperature and humidicy extrewes, confining mining environment, poor lighting, noise and vibration also contribute to miner disability but are generally not as serious as dust or carcinogens. Requirements developed for these causes of disability were termed "secondary". Table 1-2 sumarizes the health requirements for advanced coal mining systems.

\section{JUSTIFICATION OF PRIMARY HEALTH REQUIREMENTS \\ 1. Dust}

Dust and carcinogenic agents are generally harmful to the respiratory and pulmonary systems, but ingestion of different dust particle sizes and carcinogenic or mutegenic compounds results in different physiological reactions. Futhermore, different individuals vary in their reactions to these elements. The following discussion demonstrates how these variables were considered in the development of the primary requirements.

The onset and development of coal worker:' pneumoconiosis (CWP) and progressive massive fibrosis (PMF) is depentiss on the presence of coal dust of less than 5 microns diameter in the mine atmusphere (16, $22,24,27)$. The combination of dust and other mutagenic compound: released in the mining environment (such as aromesic hydrocarbons) can act as a catalyst toward the development of CWP, PMF, or other lesions (6). Cigarette smoking is also knc in to contribute to this reaction (14). Although coal workers with CWP frequently do not show a significantly altered ventilatory capacity, they do exhibit a marked decrease in oxygen transfer (11). A failure of the pulmonary aystem to transfer oxygen at at least $1250 \mathrm{cc} / \mathrm{mi}$ il prevents an individual from being gainfully employed where demands for continuous moderate physical activity are present (11). Chronic bronchitis has also been shown to be excessive in coal miners and dependent on the concentration of coal dust of greater than 5 micron particle size in the mining atmosphere (28). Therefore, a reduction in cosl dust concentration should diminish the incidence of CWP, PMF, and diseases like bronchitis and : hereby lessen excess coal worker morbidity in comparison to the rest of the working population. A more complete discussion of all of these variables is given in Appendix $A$.

The actual susceptibility of miners to CWP or PMF varies widely according to the exposure time and the individual's threshold. However, discussions with health experts in the Department of Labor (DOL), United Mine Workers (UMW), and Mining Safety and Health Administration (MSHA) seem to indicate agreement over the benefit of exposing workers to no more than $2 \mathrm{mg} / \mathrm{m}^{3}$ of dust and its relation to reducing the incidence of respiratory disability. This general agreement appears to stem from research done by the British Institute of Occupational Medicine. This research suggests that a $2 \mathrm{mg} / \mathrm{m} 3 \mathrm{dust}$ 
atandard would reduce the incidence of respiratory disability from the historical 10 to $20 \%$, to only $3 \%$ of the total working ainer population (15). That dust level is now a regulatory requirement for U.S. underground coel wines.

\section{Carcinogens and Mutagens}

Fstablishment of requirements relating to carcinogenic, mutagenic, and toxigenic compound threehold levels is extremely difficult due to the wide variation in suscuptibility of workers to pulmonary disorders or cancer $(5,14)$. Furthermore, advanced syoteas may introduce compounds into the mining environment that are carcinogenic or mutagenic, but different from the list of known compounds. In evaluating new systems, it is therefore more practical to identify these compounds on are generic level.

Stuermer and Hatch of the Lawrence Livermore Laboratories (33), and the Department of Labor (6) suggest that there are four generic groups of carcinogenic and mitagenic elements harmful to the pulwonary syatem which can be released into the mining environment. These are:

- Nitrogen aromatics (a hydrocarbon with an amonis complex present).

- Aromatic hydrocarbona.

- Oxygenated hydrocarbons.

- Metals (such as nickel or beryllium trapped within, or in gediment adjacent to, the coal seam).

These compounds and minerals are produced during the process through which coal is formed (e.g., ammonia produced by decaying organic matter, or the deposition of winerals in basins con aining organic matter which is eveatually transforwed into coal (26)). In either gas or dust form, these substances can be released into the environment through the mechanisms of hent, pressure, or the use of solvents. Because an advanced system could employ any one, or a combination, of these mechanisms to cut or haul cosl, these carcinogens and mutagens could be produced. Because of the varying susceptibility of individuals to associated diseases it is not practical to establish threshold levels $(5,14)$. Therefore, workers using an advanced mining system should not be exposed to these substances in concentrstions greater than the general poptlation's exposure during normal activities. The requirement to protect workers from an environment containing high concentrations of these substances implies that an advanced system must not allow workers to be exposed to contaminated environments, or must provide means of monitoring contaminants and removing them completely, or must reduce them to acceptable levels. One means of detecting these materials is provided in Appendix B. 


\section{E. JUSTIPICATION OF SECONDARY HEALTH REQUIREMENTS}

Secondary health requirements relate to those sources of disability that are gentially not as severe as dust or carcinogenn. For example, humidity and temperature extremen in the mining environment contribute to the incidence of influenza, pneumonia or bronchospan. However, these reepiratory problems usually arrest themselves with proper treatment if the indivitual is removed fror: the enviroment. However, the rewoval of an individual from the mining enviroment, once he has contracted pneumoconiosis, does not necesurily mean that the discase is arrested. In aimilar manner, poor lighting or noise may resice an individual's visual and hearing perceptions, but these are reparable through the use of glisses or hearing aids. Damage to the lunge can never be repaired. Though not - wajor factor in reducing mortality, the secondary requirements aitigate those aspecto of che wining environment that cause phyoiological and peychological etrese.

\section{Temperature and Humidity}

The underground mining environant frequently presents the coal ainer with a widely varying temperature and humidity atmosphere. It is diffisult to link either of these two factors to the development of specific pul. ary pathology $(10,12)$ because other factor such as diet, itress, ad lack of rest affect an individual's resistance to respiratory infection. Mevertheless, in cases of severe or chronic respiratory infection (excluding dust-related disorders) widely varying temperature and humidity conditions are ysually asociated $(11,12)$. It has been demonstrated that as a result of prolonged exposure to very high, very low or widely varying temperature, the cells of the bronchi becoms filled with fluid (10) and that in the presence of fluid in the bronchial lining cells, there is an increased incidence of virel infections of the bronchial tree, bacterial infection of the cells, and decreased cilis clearing action (12). Examples of diseases usually associated with these kinds of bronchial conditions are pneumonia, influenza, or bronchitis $(11,12)$. Asthma and cuberculosis can also be aggravated by these conditions (11). The increased incidence of pneumonia, influenza, bronchitis and asthma ang underground cosl miners (see Table 1-1 and Ref. 30) supporty the association of these diseases with prolonged exposure to temperature extremes present in underground wines (28).

Underground mining can lso present the coal miner with a high huridity atmosphere which can increase the likel ihood of developing bronchospas in certain susceptible individuals $(10,12)$. Humidity, coupled with the agsravating effecte of dust (see Appendix A.2) can account for the development of asthan ang underground coal miners (30).

Therefore, to minimize respiratory disorders associated with clewents in the aining environent other than dust and toxic compounds, any new technology should attempt to create an atmosphere 
for personnel where the relative humidity is between $50 \%$ and $75 \%$ and the temperature is between $65^{\circ} \mathrm{F}$ and $78^{\circ} \mathrm{F}$ with no extreme swings in these parameters.

\section{Acceptable Noise Levels}

Several investigators have suggested that exposure to high cumulative noise levels can result in noise-induced temporary or permanent hearing threshold shift $(3,17,25)$. Noise levels in advanced mining systems should therefore conform to the MSHA standard for safe decibel levels (21).

\section{Lighting}

Extensive research on acceptable lighting levels to minimize visual errors and eye muscle fatigue has been done by Occupational Safety and Health Administration (OSHA), MSHA, and the Joint Army, Navy, and Airforce Steering Comittee on Human Engineering Guides for Equipment Design (3). Acceptable lighting levels for the working area and access ways should conform to MSHA standards (Sections 75.1719 to 75.1719-4(21)).

\section{Working Space}

Studies of operator performance under varying space and vehicle control constraints have indicated a direct relationship between fatigue, cramped working space, and poor positioning of controls (3). other studies done on the psychological effects of operating in cramped space (18) also imply a relationship between irritability, fatigue, and space reduction. Therefore, understanding that the mining environment cannot practically allow for ideal working space conditions, it is recommended that, as a minimum, advanced systems be designed to satisfy anthropometric standards established for proper human-equipment design. Some of the key standards are shown in Appendix $c$.

\section{Vibration}

Prolonged exposure to vibration from equipment can result in "vibration disease" (25). This condition is characterized by: 1) a reduction in pain sensation, 2) a decrease in vibration sensation, 3 ) pains in the joints (particularly the hands), 4) hyperactivity, and 5) a decrease in libido (25). Because the threshold for the onset of these symptoms varies widely by individual, it is difficult to set a standard for acceptable machinery vibration levels. Nevertheless, advanced systems should be designed to include vibration damping equipment. 


\section{EVALUATING ADVANCED COAL EXTRACTION SYSTEM HEALTH CHARACTERISTICS}

Proposed advanced coal extraction systems can be evaluated for compliance with these health requirements by determining whether their health-related operational parameters satisfy the requirements. However, since the advanced system is only in the design stage, and dust concentrations or toxic gases cannot actually be measured, these operational parameters can only be estimnted. A simple three-step process is proposed for estimating the health-related operational characteristics of an advanced coal extraction system:

(1) An operational analysis of the system is performed, including a task-time estimate, to understand the degree of exposure to hazards.

(2) Health-related characteristics are estimated by comparing the system to conventional systems, or by assessing the characteristics of new designs that cannot be compared to conventional systems.

(3) An expert panel compares these estimates to the requirements to determine if the proposed advanced extraction system meets the requirements.

The first step is an operational analysis. The complete system must be examined to understand how the coal is cut, the face ventilated, the coal hauled, the roof supported, and what the operating environment is like. As part of the operational analysis, a task-time analys is is also conducted to establish the amount of interaction of the workers with the various operational elements. Once this information is assembled, the various system components, and their respective operational characteristics, are compared to similar conventional systems (and their respective health hazards) to estimate the health-related characteristics of the new system. In addition to this comparative analysis, the new system is examined for new design elements that may affect health-related characteristics but which are not comparable to conventional systems (e.g., dust containment systems, automation).

Finally, a group of experts in the field of occupational health is then consulted on the new design. They are provided the estimates of health-related operational parameters such as dust concentration, toxic substances generated, humidity, temperature, light, noise, working space, and vibration. They are then asked to comment on whether the new design can meet the proposed requirements based on the results of the analysis and their own experience with equipment. This process assists in selecting promising new designs, and does not preclude testing of new hardware to determine conformance with the requirements. 


\section{COST CONSIDERATIONS}

In the course of establishing health requirements for advanced coal extraction systems, a study was carried out to determine whether the costs of miner disability compensation would provide economic incentives to reduce mine-related diseasea. It was determined that the trend (in constant dollars) is such that, by the time advanced extraction systems are operating, disability compensation costs will no longer be a major component of production costs. Health requirements are nonetheless justified on the basis of the social and humanitarian objectives that miners should not be exposed to health hazards greater than those faced by the general working population.

The Black Lung Benefits Fund, administered jointly by the Secretaries of Labor, Treasury, and Heal th and Human Services, provides compensation for respiratory disability (7). As of mid-1979, the Department of Labor (DOL) reported spending $\$ 333$ million in cumulative monthly benefits and medical expenses (7). Discussions with the Black Lung Compensation Division of DOL indicate that a total of $\$ 1$ billion dollars could be spent for compensation by the end of 1980 or 1981 .

The potential impact of technology on reducing respiratory disability costs is sizable. Miners exposed to dust $(5$ micron size or less) over the last several decades have developed CWP at an approximate frequency of one out of every five people (13), but recent studies suggest that reducing dust levels to the MSHA standard of 2 $\mathrm{mg} / \mathrm{m}^{3}$ could reduce this incidence to approximately one in $30(15)$. Therefore, advanced technology could have considerable impact on both the incidence of respiratory disease and the cost.

Determining the total cost of respiratory disability is difficult because 1) the incidence of respiratory disease and resultant disability varies by age, exposure to dust, and susceptibility of individual miners, 2) some variables, such as rehabilitation or retraining, do not have dollar values attached to them, and 3 ) other well-defined cost variables are long-term costs. The basic variables contributing to the total cost are:

- Monthly benefits (disability compensation).

- Medical services, including

a radiologic tests.

b. pulmonary system tests.

c. medical treatment.

d. physical exams.

- Administrative costs, including

a. staff.

b. public information. 
Less defined variables wich are equally important, though often not considered as compensable, are:

- Value of leisure.

- Ripple effect within the family resulting from the disability (causing younger members to forfeit higher educational and employment goals to help conpensate for lost wages).

- Loss of personal market value when the individual attempts to find employment outside the mine.

- Cost of rehabilitation and retraining.

The present magnitude of health costs on a per ton basis was determined by dividing the total approximate 1979 expenditures for respiratory disease ( $\$ 300$ million) by the total 1979 underground production ( 218.85 million tons). This resulted in a cost of $\$ 1.37$ per ton, of which industry presently pays $\$ .50 /$ ton ( 7 ).

Several factors will affect future health care costs. Prior to 1970 , miners were exposed to dust levels in excess of the $2 \mathrm{mg} / \mathrm{m}^{3}$ standard. It 198 been projected that at least 125,000 miners have CWP as a result of prolonged exposure to excessive dust levels (13). In mid-1979, Department of Labor was paying compensation to 123,000 of those miners ( 7 ). The actual figure will probably exceed 125,000 because miners can now be compensated for other respiratory disabilities ( 7 ). In the early seventies there was also a large retirement of older miners accompanied by a large influx of new miners (8). Thus, a peak in the number of miners compensated will probably be reached soon.

In 1970 , the $2 \mathrm{mg} / \mathrm{m}^{3}$ dust standard was imposed on industry. The projected effect of requiring that dust levels not exceed 2 $\mathrm{mg} / \mathrm{m}^{3}$ is that the incidence of CWP will be reduced to $3 \%$ (15). MSHA dust control surveys indicate that since 1975, about $74 \%$ of underground sections have been able to comply with the $2 \mathrm{mg} / \mathrm{m}^{3}$ standard on a relatively continuous bas is ( 31 ). Therefore, it appears reasonable to assume that the reduction in disease frequency from .2 to .03 is feasible.

Since the incubation period for CWP is approximately 20 years (13), with the large influx of new miners in the early seventies, one would expect the next peak incidence of respiratory disability to materialize around the year 2000. But with the apparent trend toward compliance with the $2 \mathrm{mg} / \mathrm{m}^{3}$ dust standard, the incidence of respiratory disease and resultant cost (in constant dollars) should steadily decrease. If the incidence of respiratory disability is reduced by a factor of 5 or 6 (from $20 \%$ to $3 \%$, as noted in Ref. 15), and if the projected productivity increases by $17 \%$, from 10 to 12 tons per man shift (9), health costs would be reduced, in constant dollars, 
from the present $\$ 1.37$ per ton to $\$ .23$. The industry's present contribution could cover this entire amount. It is therefore clear that this approximate 17 cost component (for coal selling at $\$ 20-\$ 30$ per ton) does not offer a strong economic driver for advanced systems which might improve health conditions still more. 


\section{RETERENCES}

1. American Thoracic Society, "Definition and Clasaification of Chronic Bronchitis, Asthma, and Pulmonary Emphysema," Am. Rev. Resp. Dis.., 85: 762, 1962.

2. Armstrong, B., "Clinical-Physiologic Evaluation of Physical Working Capacity in Persons with Pulmonary Disease," Amer. Div. of Resp. Dis., Vol. 93, Pg. 90, 1966.

3. Army, Navy, Air Force Steering Comittee, Human Engineering Guide to Equipment Design, revised edition, McGraw-Hill Co., 1972.

4. Becklabe, Margaret R., Zwi, S. and Lutz, W., "Studies on the Nature and Etiology of Respiratory Disability in Wilwaterstrand Coal-Miners Free of Radiologic Silicosis," Br. J. Industr. Med., $16: 290,1959$.

5. Davies, D., "Disability and Coal Workers Pneumoconiosis," Br. Med. J., 2:652, 1974.

6. Department of Labor, "An Interim Report to the Congress on Occupational Diseases," December 1979.

7. Department of I,abor, "Black Lung Benefits Act, Annual Report, Calendar Year 1978 and January 1, 1979-June 30, 1979," 1979.

8. Energy \&nvironmental Analysis, Inc., "Analysis of the Impacts of the Coal Mine Health and Safety Act on the Coal Industry," 26 October 1979.

9. Energy Environmental Analvgis, Inc., "Forecast of Long-Term Cosl Supply and Mining Conditions: Model Documentation and Results," 7 March 1980.

10. Fraser and Pare', Diagnosis of Diseases of the Chest, Saunders Co., 1977.

11. Guyton, A., Textbook of Medical Physiology, Fifth Edition, Saunders, Co., 1976 .

12. Heitzman, E. Robert, The Lung: Radiologic-Pathologic Correlations, Mosby Co., 1973.

13. Kerr, L., "Black Lung," Department of Occupational Health, UMW, Library of Congress Catalogue No. 72-81770, 1968.

14. Kibelstis, J. A., Morgan, E. J., Reger, R., Lapp, N., Seaton, A. and Morgan, W. K. C., "Prevalence of Bronchitis and Airway Obstruction in American Coal Miners," Am. Rev. Resp. Dis.. $108: 886,1973$. 
15. Jacobsen, M., et al., "New Dust standards for British Coal Mines," Nature, London, 1979.

16. King, E. J. and Fletcher, L. M., Industrial Pulmonary Diseases, Churchill Pub., London, England, 1960 (pp. 221-231).

17. Kornilov, A. N., Irrautseva, Y. I., "Evaluation of Integration Exposure Energy Load on Aural Analyzer of Miners," Institute of Marine Transport Hygiene, Leningrad, Russia, (translation).

18. Lorenz, K., On Aggression, Harvest Books, 1966.

19. Lyons, J. P., Ryder, R., Campbell, H., and Gough, J., "Pulmonary Disability in Coal Workers Pneumoconiosis," Br. Med. J., 1:713, 1972 .

20. McCann, J., Choi, E., Yamasaki, E., and Ames, B. N., "Detection of Carcinogens and Mutagens in the Salmonella/Microsome Test: Assay of 300 Chemicals," Proc. Nat1. Acad. Sci. USA, 72:5135, 1975.

21. MHSA, "Code of Federal Regulations Title 30, Mineral Resources," United States Department of Interior, Revised as of 1 July 1976.

22. Morgan, W. K. C., "Respiratory Disease in Coal Miners," J.A.M.A., $231: 1347,1975$.

23. Morgan, W. K. C., Leyrp, N. L., and Morgan, E. J., "The Early Detection of Occupational Lung Disease," $\mathrm{Br}$. J. Dis. Chest, $68: 75,1974$.

24. Nacye, R. L., Mahon, J. K., and Pellinger, W. S., "Rank of Coal and Coal Workers Pneumoconiosis," Am. Rev. Resp. Dis., 103:350, 1971 .

25. Paranko, N. M., Yyshchisan, V. F., and Naumenko, B. S., "Stable Functional Disruptions in Miners Exposed to Permissible Levels of Vibration and Noise," Krivoy Rog Scientific Research Institute of Industrial Hygiene and Occupational Diseases, Russia (translation).

26. Park, C. F., MacDiarmid, R. A., Ore Deposits, Third Edition, W. H. Freeman and Co., San Francisco, Copyright, 1975.

27. Penman, R. W., "Conference on Pneumoconiosis: A Summary of the Conclusions from an International Conference on Coal Workers Pneumoconiosis," Asm. Rev. Resp. Dis., 102:243, 1970.

28. Rasmussen, N. L., and Nelson, C. W., "Respiratory Function in Southern Appalachian Coal Miners," Am. Rev. Resp. Dis., 102:240, 1970. 
29. Report to Medical Research Council by Committee on Aetiology of Chronic Bronchitis, "Definition and Classification of Chronic Bronchitis for Clinical Epidemiological Purposes," Lancet, 1:775, 1965.

30. Rockette, H., "Mortality Among Coal Miners Covered by the UMWA Health Retirement Funds," United States Department of Health, Education, and Welfare, Public Health Service - Center for Disease Control, NIOSH, March 1977.

31. Schlick, D., "Technical Advances for Achieving the Respirable Dust Standard," MHSA, 1980.

32. Spink, R, and Nagelschmidt, "Dust and Fibrosis in the Lungs of Coal-Workers from the Wigen Area of Luncastle," Br. J. Industr. Med., 19:118, 1962 .

33. Dr. D. Stuermer and Dr. F. Hatch, Lawrence Livermore Laboratories, University of California, personal communication, January 15, 1980. 


\section{APPENDIX A}

\section{EFFECTS OF COAL DUST INHALATION}

\section{The Effect of Coal Dust Particles of Less Than}

5 Microns on CWP and PMF

The cause of coal worker's pneumoconiosis (CWP) and progressive massive fibrosis (PMF) is inhaled particles of coal dust smaller than 5 microns in diameter $(16,22,24,27)$. Other kinds of dust particles, within the same size range, can also be inhaled. These are mineral particles that are often found within, or adjacent to, the coal seam (26). Minerals such as beryllium and zinc can assist in the development of CWP, PMF, other non-malignant respiratory diseases, and lung cancer (6). Particles larger than 5 microns are cleared at a level above the alveoli and, though they can irritate the upper bronchial tract, do not contribute to CWP or PMF (10, 12). Although, without coal dust, coal worker's pneumoconiosis would not exist, other factors are also of importance in the development of this disease. The job of the individual is an important consideration. A job requiring a high energy expenditure will require a greater air volume, thus presenting to the alveoli a greater load of coal dust per unit time. There also seems to be an individual variation in the ability of the lung to clear these smaller dust particles from the alveoli, thus yielding a varying susceptibility of the individual to the development of pneumoconiosis $(5,19)$.

A threshold exists for each individual when the alveoli can no longer clear the coal dust by the normal mechanism. (The particles are engulfed through the normal process of digesting cells and the mucus transport system clears these particles from the lung via expectoration or swallowing.) When this threshold level is overcome by an excessive load of coal dust, the engulfed coal dust particles remain in the alveoli. This yields a primary lesion consisting of a mixture of coal dust and distorted cells enmeshed in a fine network. These coal macules, when present in sufficient quantities in a sufficient number of alveoli, yield the well known radiographic abnormalities of coal worker's pneumoconiosis (CWP). When these coal macules become incorporated into the interstitial spaces of the alveoli, oxygen transfer is reduced. This mechanism accounts for the fact that disabled coal miners with CWP frequently have little or no alteration in their ventilatory capacity but demonstrate a marked decrease in oxygen transfer (11). Cessation of exposure to coal dust inhalation in these individuals usually prevents any further progression of these pathologic changes (22). However, in approximately $10 \%$ of those individuals initially developing CWP, some factors, as yet unknown, come into play causing a progressive destruction of lung tissue. The individuals developing progressive massive fibrosis (PMF) seem to have an autoimane factor aiding the progression of this disease. Autoimune factors usually result from the destruction of some of the body tissues which can initiate a reverse immunity reaction ( 11$)$. The resulting imane product attack the body's own tissues (11). Tests for factors such as anti-lung 
antibodies $(10,12,16)$ are positive in a disproportionate number of these coal workers. The lesion of PMF is usually restricted to the posterior segments of the upper lobe and the superior segments of the lower lobe. These lesions are ill-defined bundles of coarse connective tissue frequently obliterating the normal lung architecture. Stuermer and Hatch of the Lawrence Livermore Laboratories (33), suggest that nitrogen aromatics, nromatic hydrocarbons, and oxygenated hydrocarbons found in crace amounts within the coal can also contribute to the mutation of the cellular structure of lung tissue. This could materialize as lung cancer, cellular mutations similar to PMF, or other pulmonary problems.

\section{The Effect of Coal Dust Particles of Greater Than 5 Microns on Bronchitis}

The diagnosis of chronic bronchitis is a purely clinical one. The definition is arbitrary in order to have some means of separating the diagnosis of bronchitis from similar diseases such as the common cold. It was set forth by the American Thoracic Society (1) and the report to the Medical Research Council by the Committee on the Aetiology of Chronic Bronchitis (29) in 1962 and 1965, respectively. Expectoration, i.e., productive cough, must occur several days out of the month for at least 3 consecutive months, during 2 successive years. The diagnosis excludes other causes of productive cough such as asthma and pulmonary edema as well as non-productive cough. In many cases these exclusions are difficult to define and some overlap does, on occasion, occur.

Coal dust greater than 5 microns in size has been documented to be an etiologic factor in the development of bronchitis (28). Becklabe and coworkers (4) have demonstrated a direct relationship between impairment of exercise tolerance in miners with normal chest $x$-rays and the concentration of ccal dust in the mines. A study of 8,555 bituminous coal miners (14) demonstrated a statistically significant decrease in the incidence of bronchitis among non-smokers working on the surface compared to non-smoking workers at the coal face. This again confirms the etiologic factor played by coal dust in the develoment of this disease. 


\title{
APPENDIX B
}

\section{CARC INOGEN DETECTION IN ADVANCED COAL TECHMOLOGIS}

\begin{abstract}
Current coal mining technology has not caused a significant increase in cancer wortality rates in cosl workers, but it is difficult to anticipate in any prospective technology the risk inherent in the exposure of workers to trace toxic compounds, carcinogens, or mutagens $(5,19)$. It is etraightforward to opecify exposure levels for known carcinogene. However, given the length of the incubation period (20-30 years) between the carcinogenic initiation and the development of the disease, a more effective criterion than the absence of any known carcinogen should be used to establish the presence of mutagenic material. Therefore, rather than attempting to guess at possible carcinogens wich might be present as - byproduct of some as yet undefined advanced technology, and then insisting upon specificatione to eliminate them, it is proposed that any advanced technology be evaluated for the presence of mutagenic agents via laboratory teats. A highly regarded procedure available today is the Ames Salmonella tester otrain aystem (20) which has proven extremely valuable in the detection and quantization of trace levels of chemical mutagens. This method is currently being used to determine the air quality in different sections of Los Angeles. Its general applicability is based upon the topirical finding that greater than $85 \%$ of all compounds exhibiting a positive Ames test are also observed to be carcinogenic in model animal systems. The assay is $s$ iaple, inexpensive, and routinely used in numerous laboratories throughout the United States including the National Institute of Environmental Health Sciences in Research Triangle Park, North Carolina and at the University of California Laboratories in Livermore. Moreover, the Salmonella test offers the further major advantage that carcinogens or mutagens of unknown composition (as might be generated from a new technology) can be isolated and retained for additicnal analysis. Thus, promising new technology, whose application may be limited due to the production of mutagenic byproducts of unknown origin, could have such byproducts detected in early testing of the hardware, identified as to composition, and eliminated or reduced to acceptable levels before the design becomes concrete.
\end{abstract}


Table C-2. Equipaent Design Considerations (Mean Dynamic Anthroponetric Measurements to Fit Most Body Configurations, taken from Human Ensineerins Guide to Equipent Design, 1972)

Right hand, shirt sleeved, grasping reach weasured at the normal position for operating vehicle controle

Horizontal Angular Boundaries Measured in Degrees Swing from a straight Forward Position

\begin{tabular}{rl}
30 & 26.25 \\
45 & 27.25 \\
60 & 28.0 \\
75 & 28.25 \\
90 & 28.25 \\
105 & 27.75 \\
120 & 26.75 \\
& \\
\hline \multicolumn{3}{c}{ Head Angular Movement in Degrees } \\
\hline \\
Forward/Backward & 60.5 \\
Left/Right & 41 \\
Rotation Left/Right & 79 \\
\hline
\end{tabular}

